Center for Advancing Translational Sciences. 2015 [cited 2018 Nov 15]. Available from: https://ncats.nih.gov/translation/spectrum 3. $\mathrm{Hu} \mathrm{H}$, Mural RJ, Liebman MN. Biomedical Informatics in Translational Research. 1 edition. Boston: Artech House; 2008. 264 p. 4. Payne PRO, Embi PJ, Niland J. Foundational biomedical informatics research in the clinical and translational science era: a call to action. J Am Med Inform Assoc JAMIA. 2010;17(6):615-6. 5. Payne PRO, Embi PJ, editors. Translational Informatics: Realizing the Promise of Knowledge-Driven Healthcare. Softcover reprint of the original $1^{\text {st }}$ ed. 2015 edition. Springer; 2016. 196 p. 6. Richesson R, Andrews J, editors. Clinical Research Informatics. $2^{\text {nd }}$ ed. Springer International Publishing; 2019. (Health Informatics). 7. Robertson D, MD GHW, editors. Clinical and Translational Science: Principles of Human Research. 2 edition. Amsterdam: Academic Press; 2017. 808 p. 8. Shen B, Tang H, Jiang X, editors. Translational Biomedical Informatics: A Precision Medicine Perspective. Softcover reprint of the original $1^{\text {st }}$ ed. 2016 edition. S.l.: Springer; 2018. 340 p. 9. Valenta AL, Meagher EA, Tachinardi U, Starren J. Core informatics competencies for clinical and translational scientists: what do our customers and collaborators need to know? J Am Med Inform Assoc. 2016 Jul 1;23(4):835-9. 10. Anderson LW, Krathwohl DR, Airasian PW, Cruikshank KA, Mayer RE, Pintrich PR, Raths J, Wittrock MC. A Taxonomy for Learning, Teaching, and Assessing: A Revision of Bloom's Taxonomy of Educational Objectives, Abridged Edition. 1 edition. New York: Pearson; 2000.

3143

DIAMOND: A Digital Platform for Workforce Development Brenda Eakin, $\mathrm{MS}^{1}$, Elias M. Samuels ${ }^{1}$, Vicki Ellingrod, PharmD, FCCP ${ }^{1}$, Carolynn Jones ${ }^{2}$, Camille Anne Martina, PhD $^{3}$, Sarah Peyre ${ }^{3}$, Alice M Rushforth ${ }^{4}$, Haejung Chung ${ }^{4}$ and Thomas E Perorazio, PhD $^{1}$ ${ }^{1}$ University of Michigan School of Medicine; ${ }^{2}$ The Ohio State University; ${ }^{3}$ University of Rochester and ${ }^{4}$ Tufts University

OBJECTIVES/SPECIFIC AIMS: The DIAMOND project encourages study team workforce development through the creation of a digital learning space that brings together resources from across the CTSA consortium. This allows for widespread access to and dissemination of training and assessment materials. DIAMOND also includes access to an ePortfolio that encourages CRPs to define career goals and document professional skills and training. METHODS/STUDY POPULATION: Four CTSA institutions (the University of Michigan, the Ohio State University, University of Rochester, and Tufts CTSI) collaborated to develop and implement the DIAMOND portal. The platform is structured around eight competency domains, making it easy for users to search for research training and assessment materials. Contributors can upload links to (and meta-data about) training and assessment materials from their institutions, allowing resources to be widely disseminated through the DIAMOND platform. Detailed information about materials included in DIAMOND is collected through an easy to use submission form. DIAMOND also includes an ePortfolio designed for CRPs. This encourages workforce development by providing a tool for self-assessment of clinical research skills, allowing users to showcase evidence of experience, training and education, and fosters professional connections. RESULTS/ANTICIPATED RESULTS: To date, more than 100 items have been posted to DIAMOND from nine contributors. In the first 30 days there were 229 active users with more than 500 page views from across the U.S. as well as China and
India. Training materials were viewed most often from four competency domains: 1) Scientific Concepts \& Research Design, 2) Clinical Study Operations, 3) Ethical \& Participant Safety, and 4) Leadership \& Professionalism. Additionally, over 100 CRPs have created a DIAMOND ePortfolio account, using the platform to document skills, connect with each other, and search for internships and job opportunities. DISCUSSION/SIGNIFICANCE OF IMPACT: Lessons learned during development of the DIAMOND digital platform include defining relevant information to collect for the best user experience; selection of a standardized, user-friendly digital platform; and integration of the digital network and ePortfolio. Combined, the DIAMOND portal and ePortfolio provide a professional development platform for clinical research professionals to contribute, access, and benefit from training and assessment opportunities relevant to workforce development and their individual career development needs.

\section{Duke Integrated Physician-Scientist Development}

Stephanie A. Freel ${ }^{1}$, Michael Gunn, MD ${ }^{1}$, Andrew Alspaugh, MD ${ }^{1}$, Gowthami Arepally, $\mathrm{MD}^{1}$, Gerard Blobe, MD, $\mathrm{PhD}^{1}$, Jillian Hurst, $\mathrm{PhD}^{1}$, Maria Price-Rapoza, $\mathrm{PhD}^{1}$, Ashley Grantham, $\mathrm{PhD}^{1}$,

Laura J. Fish, $\mathrm{PhD}^{1}$, Rasheed Gbadagesin, $\mathrm{MD}, \mathrm{MBBS}^{1}$ and

Sallie Permar, MD, $\mathrm{PhD}^{1}$

${ }^{1}$ Duke University

OBJECTIVES/SPECIFIC AIMS: 1.Identify barriers to pursuing research for physician trainees 2.Develop a sustainable pipeline of physician-scientists at Duke 3.Coordinate physician-scientist development programs across the School of Medicine under one central Office 4.Provide infrastructure and resources for all physicianscientists 5.Increase the number of $\mathrm{MDs}$ and $\mathrm{MD} / \mathrm{PhDs}$ who pursue, succeed, and are retained in research METHODS/STUDY POPULATION: To establish a baseline understanding of the needs and concerns of physician-scientist trainees at Duke, we conducted focus groups using a standardized interview guide and thematic analysis. Findings from these focus groups were used to develop a framework for support, leading to the creation of the Office of Physician-Scientist Development (OPSD) housed centrally within the Duke School of Medicine. The OPSD integrates programs and resources for multiple populations including medical students, residents, fellows, junior faculty, and faculty mentors. Pipeline programs will also be developed to enhance research engagement in targeted student populations prior to medical school. RESULTS/ ANTICIPATED RESULTS: A total of 45 students and faculty participated in the focus groups and structured interviews $\left(1^{\text {st }}\right.$ year medical student, $\mathrm{n}=11 ; 4^{\text {th }}$ year medical students, $\mathrm{n}=11$; residents/fellows, $n=13$; junior faculty, $n=11$ ). While participants raised a number of specific issues, one key message emerged: non- $\mathrm{PhD}$ MDs in basic research felt they lacked opportunities for directed training. Moreover, they felt the need to teach themselves many critical skills through trial and error. This has led to perceptions that they cannot compete effectively with $\mathrm{PhDs}$ and MD-PhD scientists for research funding and positions. Consensus recommendations included: better guidance in choosing mentors, labs, and projects; central resource for information relevant to physician scientists; training specifically tailored to physician scientists conducting laboratory-based research; improved infrastructure and well-defined training pathways; and assistance with grant preparation. To-date, over 90 students, residents, and fellows have been identified who identify as laboratory-based physician scientists. Additional efforts are underway to identify and 